\title{
A social work study on the impact of different factors on respect to women
}

\author{
Gholam Reza Tajbakhsh $^{\mathrm{a}^{*}}$, Mohammad Reza Iravani ${ }^{\mathrm{b}}$, AllahyarArabmomeni ${ }^{\mathrm{c}}$ and HajarJannesari ${ }^{\mathrm{d}}$
}

\author{
AR T I C LEINF O \\ Article history: \\ Received April 25, 2012 \\ Received in revised format \\ 20 October 2012 \\ Accepted 22 October 2012 \\ Available online \\ October 252012 \\ Keywords: \\ Quality of life \\ Women's confidence \\ Respect for women \\ Women's talent \\ Political participation
}

${ }^{a}$ Assistant professor in Sociology, University of Grand Ayatollah Brojerdi, Brojerd, Iran

${ }^{b}$ Assistant Professor, Department of Social Work, Islamic Azad University, Khomeinishahr Branch, Daneshjou Blvd, Isfahan, Iran

${ }^{c}$ Department of Human Science of Islamic Azad University Khomeinishahr Branch, Isfahan, Iran

${ }^{d}$ MS Student, Counseling Department, Islamic Azad University of Khomeinishahr, Khomeinishahr Branch, Daneshjou Blvd, Iran

\begin{abstract}
A B S T R A C T
Quality of life plays an important role on people's life style and there are many studies to determine important factors influencing it. In this paper, we study the effect of different factors influencing respect for women including upbringing children, strengthening families, participation and community involvement, women's talent political participation increase, women's confidence in accepting responsibility and consent of the docility of marriage. The proposed study of this paper selects a sample from all female students who are enrolled in educational studies in Shiraz university, Iran and using Pearson correlation test, we measure the relationship between seven mentioned items with respect for women. The results indicate that except one case, participation and community involvement, all other factors significantly increase respect for women.
\end{abstract}

(c) 2013 Growing Science Ltd. All rights reserved.

\section{Introduction}

Quality of life plays an important role on people's life style and there are many studies to determine important factors influencing quality of life. According to Shrier and Shrier (2009) there have been dramatic changes in women's work and personal/family lives in many countries including the United States and these changes have particularly influenced white, middle-class women and women in medicine and other professions. Having a mutual respect in family relationship plays an essential role on building good and stable family partnership and in the absence of mutual respect we may expect some unwelcome incidents. Maghsoudi et al. (2004), for instance, reported some statistics on women victims of self-inflicted burns in Tabriz, Iran. According to their survey, From 20 March 1998 through 20 March 2002, a total of 412 cases of self-burning were reported to the burn center of East Azarbaijan, located in the city of Tabriz, Iran. These people were mostly young and the average age was 25.5 years and $99 \%$ of self-burning cases were female and married, housekeepers and illiterate

*Corresponding author. Tel: +989177326552

E-mail addresses: tajbakhsh_gr@yahoo.com (G.R. Tajbakhsh) 
and poor. Nearly three quarter of them had impulsive suicidal intention in their lives and the primary motivation was marital conflict. Therefore, we can conclude that it is important to learn more on how to increase mutual respect among families (Edwards et al., 2009; Protschky, 2009). Paranjape et al. (2010) investigated family violence and associated help-seeking behavior among older African American women and determined some barriers for help them including negative encounters with physicians, lack of trust in the system and dearth of age-appropriate resources.

One of important factors, which could influence family relationship is to increase women's talent. Ibeh and Debrah (2011) extended the talent development literature by studying the level of institutionalization of female talent development (FTD) practices in African B-schools, comparing this with the international best practice. They reported that African B-schools, like their international counterparts, did not have widely adopted FTD practices, and their female-male ratio was less than a third of graduate management programs. They also investigated the role of indigenous and multinational enterprises in supporting FTD. Tatli et al. (2012) emphasized the lack of research, which combines talent management, utilization of female talent and gender quotas and explained the link between talent shortages and under-utilization of female talent. They showed the relevance of gender quotas as a talent management strategy for both local and multinational companies.

Sevinç and Garip (2010) performed an investigation on the relationship between parents' child raising styles and their marital harmony with children at age 5-6 who were attending preschool in Istanbul. They studied upbringing styles in three categories including authoritative, authoritarian and permissive. Based on the results they concluded that there was a positive and meaningful relationship between authoritative upbringing and marital harmony. In addition there was a negative relationship between authoritarian and permissive upbringing and marital harmony. They concluded that as the parent's authoritative style scores increase the marital harmony scores also increases. Besides, according to their findings, as the authoritarian and permissive scores on the child raising styles increase their marital harmony scores may also decrease.

Susinos et al. (2008) performed an investigation in Cantabria, Spain, on reconstructing the history of women's education in Spain during the twentieth century, based on the school life histories of three women from the same family. Sar et al. (2010) discussed the relative importance of expanding home visitation services to incorporate strengthening family relationships for the benefit of children. They explained that home visiting programs substantially address risks of maltreatment associated with the mother and infant through providing services such as medical care, education/vocational support, and training on positive infant parenting practices. They performed a research on the effect of these relationships for children's wellbeing by considering some examples of evidence-based programs to strengthen these relationships.

Anthopoulou (2010) discussed a relative flourishing in the Greek countryside of small women's businesses engaged in the production of local traditional agrofood products and the primary question was "to what extent do these women perceive their business more as a means of supplementing family income than as a point of departure for a personal professional career?" The results of the survey carried out in the Peloponnese (2006-2007) indicated that these were small individual businesses utilizing local resources including farm production, traditional recipes and family labor.

Brook et al. (2012) investigated reunification outcomes of children of alcohol or other drug involved parents who were placed in foster care and received the Strengthening Families Program as part of their child welfare service intervention. They reported that the Strengthening Families Program participants were significantly more likely to reunify families. Liljestrand and Reatanak Sambath (2012) analyzed the evolution of some societal and health system factors based on recent national and international reports in Cambodia. The maternal mortality ratio fell from 472 per 100,000 live births in 2000-2005 to 206 in 2006-2010. The most important factors have included peace and stability, 
improved primary education, especially for girls, economic growth and poverty reduction, improved roads, improved access to information on health and health services via TV, radio and cellphones, and increased ability to communicate with and within the health system.

Martín-Fernández et al. (2009) analyzed the impact of work-family conflict as a reason for minor occupational accidents suffered by working women. They performed a survey on working women in the Madrid region, who had suffered a minor occupational accident in 2004 and reported that nearly half of the women with children believed the stress and fatigue caused by trying to combine work and family played a part in the accident. Additionally, 50\% of the women suffered after-impact because of the accident; children had to change their routine in almost 1 in 4 cases; nearly a quarter of the respondents said their work situation had been temporarily modified. This recommends for policies that encourage men and employers to contribute more to solve work-family conflicts.

In this paper, we study different factors influencing respect towards family and their engagement in family oriented businesses. The organization of this paper first presents seven hypotheses in section 2 and section 3 presents details of our findings. Finally, concluding remarks are given in the last to summarize the contribution of the paper.

\section{The proposed study}

The proposed study of this paper considers the following seven hypotheses,

1. There is a meaningful relationship between upbringing children and respect for women.

2. There is a meaningful relationship between strengthening families and respect for women.

3. There is a meaningful relationship between positive participation and community involvement and respect for women.

4. There is a meaningful relationship between women's talent and respect for women.

5. There is a meaningful relationship between political participation and respect for women.

6. There is a meaningful relationship between increase women's confidence in accepting responsibility and respect for women.

7. There is a meaningful relationship between consent of the docility of marriage and respect for women.

The proposed model of this paper is implemented on one of Iranian banks branches located in Tehran which is the capital city of Iran. The sample size is calculated as follows,

$$
N=Z_{\alpha / 2}^{2} \frac{p \times q}{e^{2}},
$$

where $N$ is the sample size, $p=1-q$ represents the probability, $z_{\alpha / 2}$ is CDF of normal distribution and finally $\varepsilon$ is the error term. For our study we assume $p=0.5, z_{\alpha / 2}=1.96$ and $e=0.99$, the number of sample size is calculated as $N=98$. We have distributed 125 questionnaire and received 120 ones. All data have been investigated using SPSS software package using Pearson correlation test. 


\section{The results}

In this section, we present details of our investigation using Pearson correlation test on all seven hypotheses.

\subsection{Relationship between upbringing children and respect for women}

The first hypothesis of this survey is associated with the relationship between upbringing children and respect for women. Pearson correlation test has been calculated as 0.096 and the level of significance is 0.041 . Therefore, we can conclude that there is a positive and meaningful relationship between upbringing children and respect for women.

\subsection{Relationship between strengthening families and respect for women}

The second hypothesis of this survey is associated with the relationship between strengthening families and respect for women. Pearson correlation test has been calculated as 0.084 and the level of significance is 0.024 . Therefore, we can conclude that there is some positive and meaningful relationship between strengthening families and respect for women.

\subsection{Relationship between community involvement and respect for women}

The third hypothesis of this survey is associated with the relationship between community involvement and respect for women. Pearson correlation test has been calculated as 0.185 and the level of significance is 0.065 . Therefore, we cannot conclude that there is any strong positive and meaningful relationship between community involvement and respect for women when the level of significance is five percent. However, when the level of significance is discounted to $10 \%$ we can say there is some positive relationship between these two figures.

\subsection{Relationship between women's talent and respect for women}

The third hypothesis of this survey is associated with the relationship between women's talent and respect for women. Pearson correlation test has been calculated as 0.812 and the level of significance is 0.024. Therefore, we can conclude that there is a strong, positive and meaningful relationship between women's talent and respect for women when the level of significance is five percent.

\subsection{Relationship between political participation and respect for women}

The fifth hypothesis of this survey is associated with the relationship between political participation and respect for women. Pearson correlation test has been calculated as 0.159 and the level of significance is 0.014. Therefore, we may conclude that there is some positive and meaningful relationship between political participation and respect for women when the level of significance is five percent.

\subsection{Relationship between women's confidence and respect for women}

The sixth hypothesis of this survey is associated with the relationship between strengthening families and respect for women. Pearson correlation test has been calculated as 0.812 and the level of significance is 0.024 . Therefore, we can conclude that there is a strong positive and meaningful relationship between strengthening families and respect for women. 


\subsection{Relationship between the docility of marriage and respect for women}

The sixth hypothesis of this survey is associated with the relationship between the docility of marriage and respect for women. Pearson correlation test has been calculated as 0.184 and the level of significance is 0.006. Therefore, we can conclude that there is a strong positive and meaningful relationship between strengthening families and respect for women.

The results indicate that except one case, participation and community involvement, all other factors significantly increase respect for women.

\section{Conclusion}

We have presented an empirical study to find the relationship between different factors for respect for women. The study designed a questionnaire and distributed among a sample university female students. The results of our survey have been analyzed using Pearson correlation ratios. Based on the results of this survey, we can conclude that upbringing child, strengthening families, women's talent political participation increase, women's confidence in accepting responsibility and consent of the docility of marriage. However the survey has not found any supporting data to believe there is any relationship between participation and community involvement and respect towards women.

\section{Acknowledgment}

The authors would like to thank all female students who kindly participated in our survey and helped us perform this survey.

\section{References}

Anthopoulou, T. (2010). Rural women in local agrofood production: Between entrepreneurial initiatives and family strategies. A case study in Greece. Journal of Rural Studies, 26(4), 394-403

Brook, J., McDonald, T.P., \& Yan, Y. (2012). An analysis of the impact of the Strengthening Families Program on family reunification in child welfare. Children and Youth Services Review, 34(4), 691-695.

Edwards, L.A., McLaughlin, J., Seman, L., \& Panichelli, J. (2009). Strengthening nutrition education for families: An evidence-based revision of operation frontline's side by side curricula. Journal of Nutrition Education and Behavior, 41(4), S26

Ibeh, K., \& Debrah, Y.A. (2011). Female talent development and African business schools. Journal of World Business, 46(1), 42-49.

Liljestrand, J., Reatanak Sambath, M. (2012). Socio-economic improvements and health system strengthening of maternity care are contributing to maternal mortality reduction in Cambodia. Reproductive Health Matters, 20(39), 62-72

Maghsoudi, H., Garadagi, A., Jafary, G.A., Azarmir, G., Aali, N., Karimian, B., \& Tabrizi, M. (2004). Women victims of self-inflicted burns in Tabriz, Iran. Burns, 30(3), 217-220.

Martín-Fernández, S., de los Ríos, I., Cazorla, A., \& Martínez-Falero, E. (2009). Pilot study on the influence of stress caused by the need to combine work and family on occupational accidents in working women. Safety Science, 47(2), 192-198

Paranjape, A., Tucker, A., Mckenzie-Mack, L., Thompson, N., \& Kaslow, N. (2007). Family violence and associated help-seeking behavior among older African American women. Patient Education and Counseling, 68(2), 167-172.

Protschky, S. (2009). The flavour of history: Food, family and subjectivity in two Indo-European women's memoirs. The History of the Family, 14(4), 369-385 
Sar, B.K., Antle, B.F., Bledsoe, L.K., Barbee, A.P., \& Van Zyl, M.A. (2010). The importance of expanding home visitation services to include strengthening family relationships for the benefit of children. Children and Youth Services Review, 32(2), 198-205

Sevinç, M., \& Garip, E.S. (2010). A study of parents' child raising styles and marital harmony. Procedia - Social and Behavioral Sciences, 2(2), 1648-1653.

Shrier, D.K., \& Shrier, L.A. (2009). Psychosocial aspects of women's lives: Work and family/personal life and life cycle issues. Obstetrics and Gynecology Clinics of North America, 36(4), 753-769

Susinos, T., Calvo, A., \& García, M. (2008). Retrieving feminine experience: Women's education in twentieth-century Spain based on three school life histories. Women's Studies International Forum, 31(6), 424-433.

Tatli, A., Vassilopoulou, J., \& Özbilgin, M. (2012). An unrequited affinity between talent shortages and untapped female potential: The relevance of gender quotas for talent management in high growth potential economies of the Asia Pacific region. International Business Review, In Press. 